\title{
¿UN CONCEJO QUE SE TRANSFORMA?: EL ANÁLISIS DE LAS RELACIONES DE GOBERNANZA DEL CONCEJO DE MEDELLÍN ENTRE 2008 Y 2011*
}

\author{
Santiago Leyva Botero** \\ Luis Fernando Agudelo Henao*** \\ Recibido: noviembre 15 de 2011 • Aceptado: mayo 24 de 2012
}

\section{RESUMEN}

Este artículo examina las relaciones de gobernanza en red del Concejo de Medellín con la sociedad civil. El propósito es explorar si se han presentado transformaciones importantes en esta corporación que permitan hablar de un rompimiento de las relaciones clientelares. Para este efecto, se analiza el concepto de gobernanza, luego se hace una revisión sobre la evolución del concepto, seguido de la aplicación de una serie de entrevistas. El artículo llega a la conclusión de que el Concejo de Medellín ha presentado cambios importantes en los últimos años, especialmente en lo referente a la capacidad de control político. Las evidencias muestran que es aún prematuro hablar de gobernanza en red en el Concejo de Medellín, pues las redes políticas siguen estando enfocadas a lograr lealtades electorales, sin alcanzar una apertura mayor a otras formas de organización de la sociedad civil.

\section{PALABRAS CLAVE}

Gobierno local, concejo municipal, representación, gobernanza, descentralización, redes políticas.

\section{CLASIFICACIÓN JEL}

H1 1, H70, H77.

\section{CONTENIDO}

Introducción; 1. Gobernanza en red; 2. Examen de las relaciones de gobernanza en red en el Concejo de Medellín en el periodo 2008-2011; 3.Conclusiones; Bibliografía; Anexos.

\footnotetext{
Este artículo de investigación es producto de los trabajos desarrollados en dos grupos: (1) Grupo de Investigación en Contabilidad y Gestión Pública de la Universidad de Medellín, clasificado en B, con el proyecto "Observatorio de Políticas Públicas del Concejo de Medellín", financiado por el Concejo de Medellín, La Universidad EAFIT y la Universidad de Medellín. Julio de 2009- noviembre 2011 y (2) Grupo de investigación Estudios sobre Política y Lenguaje (categoría Al-Colciencias), con la investigación "Las transformaciones del Estado a nivel del gobierno local. Medellín 2000-2010" desarrollada y financiada en 2011 en el marco del grupo Estudios sobre Política y Lenguaje del Departamento de Humanidades de la Universidad EAFIT.

** Administrador de Negocios, Universidad EAFIT. Maestría de Investigación en Cambio Organizacional -énfasis en sector público- Universidad de Lancaster, UK. PhD. en Administración Pública de la Universidad de Lancaster, UK. Profesor Titular - Universidad EAFIT, Miembro del Grupo de Investigación Estudios sobre Política y Lenguaje (categoría Al-Colciencias), Medellín, Colombia. Correo electrónico: sleyvabo@eafit.edu.co.

*** Contador Público, Universidad de Medellín. Magíster en Gerencia Pública, UNPSJB, Argentina. Candidato a Ph. D. en Estudios Políticos de la Universidad Externado de Colombia. Profesor de Cátedra, Maestría en Gobierno de la Universidad de Medellín, Colombia. Correo electrónico: luisfah@gmail.com.
} 


\section{A COUNCIL THAT TRANSFORMS FROM WITHIN? THE ANALYSIS OF THE GOVERNANCE RELATIONSHIP OF THE MEDELLIN COUNCIL BETWEEN 2008 AND 2011}

\section{ABSTRACT}

This article examines the relationship between governance and the Medellin Council network, the purpose is to explore if there has been important transformations in this corporation that might speak of a breakdown of client relations. For this purpose, the governance concept is analyzed followed by a concept evaluation review proceeded by the application of a series of interviews. The paper concludes that the council of Medellin has introduced important changes in recent years, especially with regards to the ability of political control. The evidence shows that it is still premature to talk about networked governance in the Council of Medellin, because political networks remain focused on achieving electoral loyalties, without reaching a greater openness to other forms of civil society organization.

\section{KEY WORDS}

Local government, municipal council, representation, governance, decentralization, political networks.

\section{JEL CLASSIFICATION}

$\mathrm{H} 11, \mathrm{H} 70, \mathrm{H} 77$

\section{CONTENT}

Introduction; 1. Network governance; Networked governance relations test for the Council of Medellin in the period 2008-2011; 3. Conclusions, Bibliography, Attachments.

\section{UM CONSELHO QUE SE TRANSFORMA?: A ANÁLISE DAS RELAÇÕES DE GOBERNANZA DO CONSELHO DE MEDELLIIN ENTRE 2008 E 2011}

\section{RESUMO}

Este artigo examina as relações de governança em rede do Conselho de Medellín com a sociedade civil, o propósito é explorar se tem se apresentado transformações importantes nesta corporação que permita falar de um rompimento das relações clientelistas. Para este efeito, se realiza uma análise do conceito de governança, logo se faz uma revisão sobre a evolução do conceito, seguido da aplicação de uma serie de entrevistas. $\mathrm{O}$ artigo chega à conclusão de que o Conselho de Medellín tem presentado mudanças importantes nos últimos anos, especialmente no que se refere à capacidade de controle político. As evidencias mostram que é ainda prematuro falar de governança em rede no Conselho de Medellín, já que as redes políticas continuam estando focadas em conseguir lealdades eleitorais, sem atingir uma maior apertura a outras formas de organização da sociedade civil.

\section{PALAVRAS CHAVE} Governo local, Conselho municipal, representação, governança, descentralização, redes políticas.

\section{CLASIFICAÇÃO JEL} $\mathrm{Hl}$ 1, H70, H77.

\section{CONTEÚDO}

Introdução; 1. Governança em rede; 2. Exame das relações de governança em rede no Conselho de Medellín no período 2008-2011; 3.Conclusões; Bibliografia; Anexos. 
¿Un Concejo que se transforma?: el análisis de las relaciones de gobernanza del Concejo de Medellín entre 2008 y 2011

\section{INTRODUCCIÓN}

Las reflexiones sobre los concejos han sido unas de las grandes ausentes de la discusión sobre el proceso de descentralización. Como señala Barberena (2010, p. 69), "tal vez una de las mayores preocupaciones radica en la poca evolución lograda en términos de depurar y mejorar la calidad de los cuerpos colegiados". El reto es central para el análisis del Gobierno local pues según lo afirma el mismo Barberena (2010, p. 69) "los debates y propuestas que surgen en el seno de estas corporaciones son muy pobres y se anteponen claramente las prioridades particulares a debates sobre el bien general". De acuerdo con Leal (1989) y Gutiérrez (1998), esto implica señalar que al evaluar el avance de la descentralización política, también se debe examinar si los concejos han podido dejar atrás las relaciones clientelares que los caracterizaron en el pasado para crear nuevas formas de participación y de representación.

Autores como Escobar (2002), Gutiérrez (1998) y Gutiérrez (2010) argumentan que la participación en Colombia ha avanzado poco, e incluso ha sufrido procesos de retroceso después de los experimentos de los años noventa. Según González y Velásquez (2003) esto ha implicado que en muchos casos no haya pasado de ser más que una participación atada a procesos de consulta, sin posibilidad de decisión o ejecución. Pero, si lo que ha ocurrido con la participación (individualmente considerada) es que se ha estancado, lo que ha pasado con la posible imbricación entre representación política (ediles, concejales, diputados, representantes, senadores) y participación es mucho menos claro. Esto sugiere que un campo por explorar es el de las relaciones entre participación y representación, y en particular los avances de esta relación a la luz de la débil articulación de la participación ciudadana y la incipiente transformación creada por las reformas descentralizadoras en las corporaciones locales. Dado lo anterior, este artículo examinará el período 2008-2011 del Concejo de Medellín, tratando de observar qué cambios de interés se han dado sobre la mencionada relación.

Hablar de transformación cuando se habla de concejos resulta para muchos algo más que contradictorio. Al respecto, Gutiérrez (2010) sostiene que la mayoría de Concejos en el país siguieron en las manos de los partidos tradicionales. Esto implicó que en el caso de las grandes ciudades en las que se experimentaron transformaciones positivas (Bogotá y Medellín), estos cambios se dieran en la modernización del Gobierno y no en la de los concejos locales. Como señala Gutiérrez (2010, p. 32) "la descentralización y la Constitución de 1991, junto con otras reformas asociadas de gran importancia (el Estatuto Orgánico de Bogotá), habian aumentado el poder del ejecutivo subnacional (alcaldía y gobernación) a costa de concejos y asambleas". Esto implicó que a los mismos concejos les fueran retirados su control sobre la tesorería del municipio y la definición de proyectos, a través de la Ley del Voto Programático, de la Ley 131 
de 1994 (CR, 1994), y la Ley Orgánica de Planeación, Ley 152 de 1994 (CR, 1994). Asimismo, Martin (2012) señala que a los Concejos les fue retirado en 1991 el control de auxilios que les asignaban los alcaldes a los concejales desde 1968 para lograr el dominio político de estas corporaciones.

Sin embargo, como señala Martin (2012, p. 294) las reformas de los noventa no buscaban disminuir el poder de los concejos como tal, sino reorientar su rol buscando separar a los mismos de las labores de coadministradores de tal manera que su función se pudiera concentrar en el control político. Para esto, Martin (2012, p. 294) apunta que se "anuló la participación de los concejales en las juntas de las empresas municipales de servicios públicos", se introdujo la remuneración directa con honorarios por sesión que son equiparables al salario diario del alcalde, y en el caso de Medellín, según Martin (2012, p. 295), otros incentivos como "oficinas, gastos de operación, representación, transporte, y pago de asesores y secretarias". Finalmente, se prohibió que un concejal, de manera paralela, ocupara otros cargos de elección como diputado, representante o senador, de tal forma que se le diera total prioridad y se profesionalizara el puesto de concejal.

Todo lo anterior dejó a los concejos con muchas menos herramientas de poder directo, pero con un mayor estatus político y un nuevo rol expresamente dirigido hacia el control político. Sin embargo, en términos prácticos, el Concejo quedó con cierta capacidad para bloquear acciones del ejecutivo, lo cual hacía importante la conformación de coaliciones de apoyo a los gobiernos de turno. El papel específico de estas coaliciones empezó a depender en gran medida del tipo de relación que se establecía con el ejecutivo, como señala Gutiérrez (2010, p. 33) "dándole grandes incentivos al ejecutivo para que comprara a sus miembros con prebendas para facilitar los trámites de sus iniciativas". Esto implica que si bien las labores de coadministración directa desaparecieron, los concejales siguieron teniendo importancia en la definición de proyectos y en el manejo de la burocracia. En cualquier caso las reformas de los noventa requirieron que los concejales aprendieran el lenguaje de los proyectos y del plan de desarrollo, y que de alguna manera empezaran a hablar de metas, indicadores e impactos. Es así como Martin (2012) sostiene que no dejaron de ser mediadores de intereses, pero, al menos en el caso de las grandes ciudades, debieron tecnificar su labor.

Uno de los impedimentos grandes para la tecnificación de los concejos ha sido la fragmentación de la acción de cada concejal. Al respecto Pizarro (2002) señala que la Constitución de 1991 amplió la fragmentación de los partidos. Luego, según Botero y Rodríguez (2009), las reformas del Acto Legislativo 01 de 2003 (CR, 2003) crearon partidos más grandes, pero no necesariamente fuertes, dado que el voto preferente le da poco control a las directivas de los partidos sobre las colectivida- 
¿Un Concejo que se transforma?: el análisis de las relaciones de gobernanza del Concejo de Medellín entre 2008 y 2011

des, asunto que tampoco se logró superar con la Ley de bancadas de 2005 (CR, 2005). Así con partidos débiles, concejales que trabajan en solitario y ejecutivos locales fortalecidos, se puede suponer que el desbalance técnico y la capacidad de control político de los concejales sobre los gobiernos locales sigue siendo muy limitada.

Por otro lado, Leal (1989) señala que los cambios de la última década han llevado a que un amplio número de políticos fusionen la estrategia de favores, lealtades y trámites del llamado clientelismo moderno, con la de asignación, según plantea Gutiérrez (2010), de contratos y cooptación de rentas del nuevo clientelismo. Este tipo de orientación cierra el interés de los concejos a la sociedad, pues su función permanece exclusivamente relacionada con aquellos grupos o clientelas que les aseguran su reelección o con aquellos contratistas que les ayudan a mantener su flujo de recursos. Al contrario de esta tendencia, el interés de este artículo es explorar la manera como los diferentes grupos de la sociedad se ven o no articulados al Concejo de Medellín en el período mencionado. Esto supone indagar si efectivamente este Concejo responde más a dinámicas de nuevo clientelismo o si, por el contrario, ha logrado abrirse a la sociedad integrando dinámicas participativas en su función de representación.

El objetivo de este artículo es examinar qué ha pasado con la relación entre la sociedad civil organizada y la Corporación. Se trata entonces de examinar los avances dados en el Concejo de Medellín por articular la voz y los intereses de los actores sociales a la agenda y a las decisiones del Concejo de Medellín. Lo anterior lleva a que se deba ahondar primero en entender cómo se puede explorar la articulación de la representación y la participación política. Para esto se propondrá el término gobernanza en red para iluminar aspectos importantes de esta posible relación.

Con estos objetivos en mente, el artículo fue divido en tres partes. La primera está relacionada con el análisis de la categoría conceptual de la gobernanza, y en especial con la gobernanza en red. Este acápite pretende explorar cuáles son los retos que crean los cambios traídos por las reformas de mercado y de activación de la sociedad civil (participación) sobre las organizaciones de representación. Este asunto reflexiona en torno al papel de las corporaciones de representación, en la medida en que las sociedades actuales tienden a derivar responsabilidades de mediación social, que antes estaban en manos del Estado, hacia mecanismos provenientes de la movilización social y la regulación del mercado. Esta migración (o al menos creciente coexistencia) de la burocracia pública hacia otros mecanismos de coordinación (mercado y sociedad organizada) implica grandes preguntas sobre los cambios que son necesarios en los organismos de representación política para poderse ajustar a los nuevos retos políticos. En este sentido, el giro hacia la gobernanza es mucho 
más que el giro hacia la participación, pues este sirve también para reflexionar sobre los cambios necesarios en los concejos y en la representación política.

En la segunda parte se describe el proceso de evolución del Concejo durante el período 2008-2011. En esta sección se muestran las muy limitadas conexiones que tenían los equipos de los concejales con la sociedad civil organizada cuando fueron entrevistados por primera vez para esta investigación en 2009. A partir de ahí el trabajo siguió los esfuerzos de la Corporación por auto-reformarse con nuevos mecanismos de apoyo a la tarea del concejal, que la han llevado a tener relaciones directas con dos universidades, más de treinta observatorios de ciudad y con casi cuarenta ONG. Esto, como se mostrará, ha llevado a que el Concejo se empiece abrir a más organizaciones y a la sociedad misma, de manera que adquiera una mayor capacidad para cubrir más temas de una manera un poco más técnica y sistemática. En este sentido, este artículo mostrará que el caso del Concejo de Medellín constituye un caso de interés nacional.

El artículo termina por concluir que aún parece pronto para hablar de que el Concejo de Medellín rompió con la inercia de la representación tradicional. Los esfuerzos por avanzar en la conformación de redes de gobernanza que prioricen los vínculos sociales con la sociedad civil organizada son todavía débiles y las redes jerárquicas tejidas alrededor de la mediación de favores son aún fuertes. Se concluye que si bien existen cambios, es necesario mejorar los niveles de reciprocidad, funcionalidad y colaboración entre los equipos de apoyo legislativo y la sociedad civil. En este sentido, los bajos niveles de cualificación e institucionalización de los mecanismos de apoyo técnico han sido un problema, que visto de otra manera se explica desde la dificultad para tomar decisiones que beneficien a la corporación (y no para los 21 concejales entendidos de forma individual). Lo anterior se evidencia en que los presupuestos del Concejo no conducen a grandes apuestas transformadoras, sino que son parcelados en pequeñas inversiones de bajo impacto. Como complemento de lo anterior, la inflexibilidad fiscal dada por la Ley 617 de 2000 (CR, 2000) ha impedido pensar en que el Concejo mejore sus capacidades técnicas y de interacción con la sociedad, a medida que aumenta el presupuesto de la ciudad.

\section{LA GOBERNANZA EN RED}

Las relaciones de gobernanza requieren el paso hacia cierto tipo de redes que son menos verticales y autoritarias, y que, a su vez, presuponen la fragmentación mayor del poder local y la necesidad de unir capacidades (coordinar) para poder lograr objetivos. Así, una red centrada de manera vertical en un concejal, muy similar a las del viejo clientelismo político, podría carecer de la amplitud y del marco orga- 
¿Un Concejo que se transforma?: el análisis de las relaciones de gobernanza del Concejo de Medellín entre 2008 y 2011

nizacional horizontal que permita la conexión de actores que se necesitan entre sí. Para Leal (1989, p. 7) este tipo de redes clientelistas se caracterizan por constituir "una relación siempre asimétrica, que se apoya en la diferencia de poder entre las partes". Esta relación, como señalaba Schmidt (1974), citado por Leal (1989, p. 6), funcionaba en el clientelismo como relaciones entre agentes que operan "en tres niveles; el primero, como relaciones entre dos personas, el segundo, como conexiones entre agregados de personas y patronos o burócratas, y el tercero, como 'interfaces' que vinculan comunidades enteras a la sociedad". Así, una de las características de la gobernanza en red es la transición hacia redes más horizontales, con redes de actores (no personas), autorganizados, y en medio de relaciones más pluralistas con intereses múltiples. Estas redes presuponen una autoridad menos vertical y con mayor capacidad de interacción y de influencia mutua. Igualmente, Gutiérrez (1998) sugiere que todos los actores son interdependientes para poder lograr ciertos objetivos, lo que implica una posición menos central que la que ocupan los concejales en las redes clientelares

A partir de lo anterior, Parker (2007, p. 118) plantea que la mayoría de la literatura de la gobernanza centra su análisis de las redes en tres elementos fundamentales: la confianza, la reciprocidad y la identidad común, como puntos clave en el desarrollo de la función de coordinación en la dirección y formación de la conducta. De esta manera, Parker (2007, p. 124) apunta que una red de gobernanza (al contrario de una clientelista) se caracteriza por una alta densidad de actores que se interrelacionan, una fuerte identidad de los actores en red, y relaciones de confianza y reciprocidad. Así, es importante distinguir gobernanza en red de otras formas de redes, que tienen vínculos entre los actores. Este artículo debe analizar si las redes que se tejen desde el Concejo han logrado construir unas relaciones más horizontales, colaborativas y con identidad o si, por el contrario, las reformas ya mencionadas han tenido un bajo impacto sobre las relaciones jerárquicas de clientela.

Es necesario entonces señalar que para que florezcan formas de gobernanza en red desde una corporación representativa como lo son los concejos en Colombia, se deben generar cambios importantes sobre las formas de coordinación preexistentes, más verticales y clientelistas. Así, para que los actores sociales y los mismos concejales encuentren alguna utilidad en trabajar en red es necesario que los concejales sientan que con su trabajo individual no es posible tener una clara visión de los problemas y las soluciones. Así, en una red de gobernanza, anota Parker (2007), los miembros se empiezan a ver como una pequeña parte de un todo más grande. Siguiendo a Pierre y Peters (2000), para que existan relaciones de gobernanza local funcionales es necesario entender que todas las discusiones del giro hacia la gobernanza que se han dado en Europa parten de la pérdida de centralidad del Estado por la activación del rol de los mercados y de la sociedad. 
Lo anterior implica, como lo señala Parker (2007, p. 115), que el término gobernanza está relacionado no solamente con el número crecientes de ONG locales, sino también con la expansión de las alianzas público-privadas, el incremento de los subcontratistas que participan con el Estado en la prestación de servicios, y la expansión de la participación comunitaria con iniciativas como los presupuestos participativos. En este sentido, se refiere, y no solo de forma exclusiva a la activación del rol de la sociedad en algunas tareas de gobierno, sino también a la activación del mercado. Este último pasa a ejercer un papel importante en la coordinación de muchos asuntos públicos por reformas como las privatizaciones y la contratación con el sector privado. La reformas de gobernanza entonces se deben entender dentro de dos tendencias que se podrían dibujar en tensión entre sí, es decir, aquellas más cercanas al neoliberalismo que llevan a un mayor rol de los mercados, y aquellas adyacentes a discursos más reivindicativos (de izquierda, ambientales, etc.) que han tratado de darle un mayor peso a la sociedad.

\subsection{Gobernanza en red y las corporaciones de representación política}

Las reformas que abrieron el espacio para los cambios que se han denominado como gobernanza también pueden impactar la tradicional democracia representativa y a los concejos, que son el motivo de preocupación de este artículo. En este contexto el rol desempeñado por los concejales adquiere mayor trascendencia, de acuerdo con Berg y Rao (2005, p. 5) se establecen tres roles importantes: en primer lugar, los concejales pueden jugar un papel clave en asegurar o posibilitar la participación de los líderes no políticos en la toma de decisiones; en segundo lugar, los concejales pueden asegurar la sostenibilidad de las organizaciones de la sociedad civil que juegan un papel importante en la gobernanza, de forma que se impulse su expansión (aún cuando estas sean críticas del ejecutivo); finalmente, los concejales pueden jugar un papel en promover la profesionalidad y el diseño institucional de las redes de políticas públicas que se encuentran por fuera de la administración, pero que pueden ser parte fundamental de la acción pública.

Lo anterior señala que un concejo que se adapte a la nueva realidad de la gobernanza puede tener funciones relacionadas con asegurar la participación, la sostenibilidad y el grado de profesionalismo de las organizaciones de la sociedad civil. Un concejo que se adapte al surgimiento de más actores sociales que están directamente, o no, vinculados con el control político asume funciones que le ayudan a cultivar la gobernanza. Así, autores como Sorensen (2006) y Jessop (2002) sostienen que estas funciones que ayudan a darle sostenibilidad e incidencia a las organizaciones de la sociedad civil se conocen para algunos autores como tareas de meta-gobernanza, es decir, la gestión para la sostenibilidad de la gobernanza. Para 
¿Un Concejo que se transforma?: el análisis de las relaciones de gobernanza del Concejo de Medellín entre 2008 y 2011

Sorensen (2006, p. 98) las funciones de meta-gobernanza de un concejo requerirían el abandono del imaginario del Estado monopolista en la toma de decisiones, para pasar a aceptar que el Estado se ha convertido en complejo institucional diferenciado, fragmentado y pluri-céntrico que lleva a cabo su gestión a través de las redes más o menos formalizadas donde la línea divisoria entre el Estado y la sociedad se vuelve borrosa

Todo esto implica que el concepto de gobernanza en red, cuando es asociado a la labor de los concejos, le apunta a explorar la manera como el mismo concejo cultiva a los actores sociales que juegan un papel importante en el control político. En este sentido, incentivar el control político de la ciudadanía debería ser una función misma de los concejos, más que de las alcaldías, ya que estas últimas tienen pocos incentivos para controlarse a sí mismas. Este modelo de gobernanza en red plantea que es entonces alrededor del concejo de una ciudad desde donde se debe articular y nutrir el papel de la sociedad en el control político. La función del concejo, además de ejercer su labor directa de control (apoyada además por las contralorías y personerías), estaría apalancada en todo el esfuerzo de una sociedad civil más activa que no necesita que la representen en el mismo viejo sentido, sino, más bien, que le ofrezcan canales y mecanismos reales para hacer oír su voz.

Así, Meuleman (2008, p. 26) afirma que bajo el antiguo modelo del Estado burocrático-weberiano que incluía los principios de la jerarquía, la toma de decisiones escalonada, y el seguimiento estricto de normas y reglas, era claro que los concejales quedaban en un rol privilegiado en la sociedad, pues eran de alguna forma una de las puertas de entrada a la acción del Estado en la dimensión local. Sin embargo, con una buena parte de las funciones públicas ya por fuera de la Administración local en muchas ciudades del mundo (sobre todo aquellas que vivieron las reformas conocidas como Nueva Gestión Pública)', se hace importante empezar a desarrollar nuevas formas de entender la acción de los concejos. Es así como, al menos en el caso europeo, se habla, según Sorensen (2006, p. 98), de la labor de meta-gobernanza de los concejos sobre las redes, que llevan a que los concejales estén más comprometidos, entre otras cosas, con las tareas de "apoyo y facilitación a la participación", así como con el diseño institucional de la regulación y la auto-regulación de los mercados, más que con las labores de intermediación directa con el ciudadano.

\footnotetext{
El lector debe pensar sobre todo en aquellas ciudades en las que se privatizaron los servicios públicos. Pero igualmente en aquellas ciudades en las que las nuevas dinámicas de NGP dejo gran parte de la acción pública en manos de las redes de contratistas, con o sin ánimo de lucro, constituyendo un escenario mucho más complejo y si se quiere pos-burocrático.
} 
Todo esto implica que para analizar las transformaciones en los concejos a la luz de los cambios involucrados en la literatura de gobernanza en red, será necesario indagar por las relaciones entre los políticos (concejales) y los actores sociales organizados. Esta relación se deberá mirar desde el punto de vista de la manera como los concejales y sus equipos interactúan con la sociedad civil organizada, y el efecto que estas interacciones tiene sobre sus propias agendas. Esta pregunta por la interacción hace también referencia al debate clásico del análisis político urbano entre el elitismo y el pluralismo. El pluralismo mostró que la fragmentación del poder llevaba a que ningún actor (o conjunto de actores) tuviera un dominio completo sobre la agenda (ver Dahl, 1961 y Polsby, 1960). Así, la gobernanza retoma ese supuesto de la fragmentación y lo profundiza, lo cual en el caso del concejo implicaría pensar en que este ya no tiene el monopolio sobre la definición de po líticas y proyectos, sino que debe apoyarse en otros actores (y en la sociedad civil organizada) para definir políticas.

\subsection{Esquemas gobernanza en red alrededor de las unidades de apoyo de los concejales de Medellín 2008-2011}

El Concejo de Medellín es una organización compuesta por 21 concejales con sus respectivos equipos de apoyo ( 2 a 5 personas), tres unidades (jurídica, de comunicaciones, y de archivo), y grupos de asesoría para las tres comisiones permanentes existentes (planeación, asuntos fiscales, asuntos generales). Su funcionamiento se organiza en plenarias y en tres comisiones que tratan temas específicos. El presupuesto del Concejo de Medellín asciende a USD\$6 millones anuales, y se encuentra regulado por la Ley 617 del 2000 (CR, 2000). Esta ley formulada en medio de una crisis fiscal de las unidades subregionales de gobierno a principios de la década de 2000, limita el crecimiento del presupuesto de los concejos, lo que lleva a un gasto bastante inflexible y que, a su vez, restringe la posibilidad de emprender nuevos proyectos que se salen por fuera de la estructura orgánica del concejo, y que no dependen directamente de los equipos individuales de los concejales o de las funciones asignadas a las comisiones.

De acuerdo con Leyva (2010) y Martin (2012), en contraste con estas capacidades relativamente limitadas del concejo para cambiar su estructura y funciones internas (todas ellas ordenadas por leyes nacionales), la Administración municipal de Medellín (en cabeza de un alcalde electo por voto directo) ha sufrido en la última década una serie de cambios importantes en la amplitud funcional, su capacidad fiscal, y la complejidad de sus labores. En cuanto a lo primero, la Alcaldía ha ampliado el número de secretarías, y la cantidad de componentes y programas que existen dentro del plan de desarrollo cubre nuevas áreas y llega a muchos más espacios de la ciudad. 
¿Un Concejo que se transforma?: el análisis de las relaciones de gobernanza del Concejo de Medellín entre 2008 y 2011

Por otro lado, la capacidad fiscal se ha triplicado (en pesos constantes de 2008) desde principios de la década del 2000. En cuanto a la complejidad, los programas han incorporado un nivel técnico más amplio en la medida que las políticas públicas de la ciudad se han ido cualificando. Todo esto implica que la labor de seguimiento y control político de la Administración local se ha hecho cada vez más retadora.

De allí que se dé un rápida expansión de la información de monitoreo. Desde mediados de los noventa, cuando se reglamentó la Ley 130 de 1994 (CR, 1994), se inició con la elaboración de planes de desarrollo formales que contienen proyectos y metas, y un presupuesto discriminado. Todo esto ha posibilitado mejorar el seguimiento de objetivos y la ejecución presupuestal. Por dar un ejemplo, un programa del plan anterior como Medellín Solidaria tenía más de 80 proyectos diferentes que influían sobre cientos de miles de personas. Cada uno de estos proyectos tenía, a su vez, indicadores específicos de cumplimiento lo cual posibilitaba hacer su seguimiento. Pero el número de líneas, componentes y programas ha venido también en rápida expansión hasta llegar a unos 530 proyectos en el plan de desarrollo de 2008 a 2011. Esto implica que el concejo que continua con 21 miembros debe hacerle seguimiento cada vez a un número mayor de proyectos.

Esta expansión de fines, objetivos y programas ha llevado también a una expansión de los indicadores de seguimiento, con unas seiscientas unidades en el plan de desarrollo 2008-2011. Así, Castro (2006) afirma que de manera similar al proceso que vivió el monitoreo al plan nacional de desarrollo entre 1995 y 2004, los indicadores se han venido expandiendo sin límites en el ámbito local, y sin tener muy claro cuál era la información necesaria para el monitoreo, y los indicadores que se debían establecer. De esta manera, para el Concejo se ha hecho más fragmentada la información y más complejo el análisis de la ciudad.

Además de lo anterior, la consolidación de redes de política pública con fuerte presencia de la sociedad civil y el sector privado también ha implicado un salto cuantitativo en el volumen de información a analizar, y por lo tanto, en el reto para el control político del Concejo de Medellín. Por ejemplo, en los últimos cinco años han surgido en la ciudad más de veintiséis observatorios que se dedican a evaluar y seguir diversos campos de políticas públicas. Estos observatorios han producido en los últimos cinco años más de 10000 páginas de documentos, estudios, libros, memorias de eventos, etc. Se podría señalar también que la Federación Antioqueña de ONG (FAONG) tiene más de 120 organizaciones agremiadas, muchas de ellas con mayor conocimiento en muchos temas que el mismo Concejo.

Todo lo anterior abre la pregunta sobre sí el Concejo de Medellín se ha transformado para abrirse a esa diversidad. De todas maneras es claro que existen 
una serie de límites (políticos, presupuestales, técnicos) que pueden dificultar esa transformación. El reto es entonces examinar sí el Concejo de Medellín se ha abierto a redes más amplias de las que configuran los mismos círculos de poder de cada uno de los concejales. Esta es una pregunta que se puede abordar desde el marco de la gobernanza en red que ha sido explicado más arriba. Esta cuestión servirá para explorar las posibles transformaciones del Concejo de Medellín, no solamente desde un punto de vista técnico, sino también de las amplias implicaciones sobre el poder urbano que tienen los cambios sobre los que se indaga en este artículo.

\section{EXAMEN DE LAS RELACIONES DE GOBERNANZA EN RED EN EL CONCEJO DE MEDELLÍN EN EL PERIODO 2008-2011}

El primer ejercicio que se realizó en el Concejo de Medellín para llevar a cabo este estudio consistió en examinar hasta qué punto los concejales realmente estaban conectados con las discusiones que se hacían por fuera de la Corporación. Para ello se decidió examinar la manera como los concejales gestionaban la información con la que preparaban los debates, con entrevistas de 30 minutos a 15 unidades (de las 21 existentes) de apoyo de los concejales entre el 19 y el 20 de agosto de 2009, los nombres de estos concejales se pueden ver en el Anexo A. Si se recuerda, esta metodología se acerca a aquella utilizada por Dahl (1961) para examinar cómo diferentes grupos influyen en políticas públicas como la educación y el desarrollo urbano. En el fondo se trata de establecer hasta qué punto los concejales tomaban entonces sus decisiones de manera aislada, o conectada con otros actores de ciudad.

En esta línea, Dahl (1961) resaltaba que la fragmentación del mundo moderno construía un tipo de política que se caracterizaba por la lucha de intereses. En su libro ¿Quién gobierna?, Dahl (1961) analizó la toma de decisiones en áreas como la transformación urbana, la educación pública y las nominaciones políticas, con el fin de estudiar la manera como distintos grupos influían en las decisiones. Dahl (1961) realizó un trabajo etnográfico en el Concejo de New Haven (entre otras instituciones) para determinar hasta qué punto la toma de decisiones en la ciudad era influida por diferentes grupos de interés. Los hallazgos de Dahl (1961, p. 163) mostraron que si bien existían individuos con más influencia, "la mayoría de los ciudadanos... poseía un grado moderado de influencia". En el caso de este artículo, el propósito es entender si los argumentos de los concejales eran o no influidos por las discusiones que se daban fuera del Concejo mismo, y si los "policy papers" que se escribían en diferentes observatorios y ONG de la ciudad realmente si influían en el punto de vista del concejo. 
¿Un Concejo que se transforma?: el análisis de las relaciones de gobernanza del Concejo de Medellín entre 2008 y 2011

Los resultados arrojados en este ejercicio corresponden al 71,4 \% del total de las Unidades de Apoyo en el Concejo de Medellín, una muestra representativa que permitió entonces conocer el grado de distanciamiento que existía entre los concejales y la sociedad civil organizada. La entrevista realizada indagó por la configuración del equipo de trabajo de cada concejal, el grado en el que este se apoyaba en otros actores para recolectar su información, y la manera misma en la que buscaba información.

En principio es importante aclarar que cada concejal tiene derecho a que el concejo le financie su propia unidad de apoyo. Para esto el concejo destinaba en 2011 unos diez millones de pesos mensuales por concejal que deben ser pagados por medio de contratos temporales a los asistentes de cada equipo. Estas unidades suelen estar conformadas por diversos miembros entre los que se encuentran una secretaria que organiza la parte administrativa y la agenda; los asistentes políticos que están conformados por líderes barriales o personal de atención al público, y finalmente, los asistentes de gestión que pueden articularse (o no) con organizaciones que le brindan información al concejal.

Según los resultados de la encuesta, las actividades que más realizan estos asistentes técnicos son el acompañamiento en debates y plenarias (un 60 \%), la búsqueda de información (un $53 \%$ ), el acompañamiento en comisiones accidentales y las reuniones con el grupo de trabajo (un 33 \%). Ahora, si bien la búsqueda de la información es una tarea básica de los asistentes técnicos de los concejales, es importante examinar cómo estos obtienen su información. En la encuesta se pudo constatar que la mayoría de los equipos hacía el rastreo a través de bases de motores de búsqueda o del rastreo de información en lugares físicos. Asimismo, se pudo ver que menos del 50 \% de los equipos hacía algún tipo de trabajo de campo, búsqueda de antecedentes y entrevistas con expertos ajenos a la Alcaldía.

En cuanto a la información formal ${ }^{2}$ que examinaban estos equipos en 2009 se puede señalar que esta se limitaba a la que arrojaban los motores de búsqueda en línea y a la que proveía la Administración municipal de Medellín a través de un cuestionario que el mismo Concejo les enviaba a los funcionarios con quince días de anterioridad a la plenaria. Destaca que solo dos equipos utilizan memorias de eventos, y solo cuatro, informes de prensa. Esto arroja un panorama donde el Concejo se presenta aislado de las redes de gobernanza local y hasta ese momento muy centrado en la información que viene desde la misma administración, o desde las redes de contacto interpersonales de los concejales y equipos de apoyo. Dentro

Se habla de información formal como aquella relacionada con información pública, que no depende de las redes políticas del concejal.

Semestre Económico, volumen 16, №. 33, pp. 181-206• ISSN 0120-6346, enero-junio de 2013, Medellín, Colombia 
de esta información oficial resalta que, aparte de la Alcaldía, las mayores fuentes de información son: la Personería de Medellín (80 \%), la Contraloría General de Medellín (80\%), y las Entidades Descentralizadas del nivel municipal (80\%).

Tabla 1. Instituciones que proporcionan información

\begin{tabular}{|l|c|}
\hline $\begin{array}{c}\text { Dependencias de la Administración que proveen información al Concejo } \\
\text { de Medellín }\end{array}$ & $\begin{array}{c}\text { ¿Cuántas Unidades de apoyo } \\
\text { consultadas usan información de } \\
\text { la dependencia? }\end{array}$ \\
\hline Personería & $80 \%$ \\
\hline Contraloría & $80 \%$ \\
\hline Secretarías & $100 \%$ \\
\hline Entidades descentralizadas & $80 \%$ \\
\hline ONG, gremios, y otras. & $47 \%$ \\
\hline ¿Trabaja con algunos observatorios de la ciudad? & $20 \%$ \\
\hline
\end{tabular}

Fuente: elaboración propia

Al contrario, como sugiere la tabla, se evidenció que menos del $50 \%$ de los concejales trabajaba con organizaciones que entrarían dentro de lo que se podría llamar gobernanza. Este indicador es especialmente bajo si se miran las interacciones con los observatorios de ciudad que solo llegaban al $20 \%$ de los concejales. Esto indicaba que a pesar de los importantes avances en la ciudad de Medellín para configurar unas capacidades en el monitoreo y la observación de lo público (ver Leyva y Tabares, 2011), los observatorios habían tenido hasta 2009 un impacto muy bajo sobre el Concejo. Quizá esto sugiera que los concejales no sentían que era necesario interactuar con otros actores, o bien porque tenían su posición de poder relativamente asegurada, o bien, porque seguían orientados bajo arreglos clientelares en la que ellos mismos ocupaban la posición central.

En otras palabras, el Concejo sostiene y financia unas unidades de apoyo que en su gran mayoría están orientadas a manejar las relaciones políticas de los concejales con su comunidad de una manera más tradicional. Aún en los casos en los que algunos concejales tienen asesores más técnicos que son encargados de preparar debates y asistirlos en la formulación de proyectos de acuerdo, las capacidades de estos por actuar de manera tan fragmentada (concejal por concejal) no dejan de ser débiles y meramente reactivas a los debates de turno. Este aislamiento del Concejo de las universidades, el sector privado, los gremios y las ONG se acentuaba entonces (ver gráfico 1) en la medida que los contactos de los concejales para conseguir 
información estaban basados en redes muy personales e información recaudada en forma individual por cada equipo.

Gráfico 1. Origen de la información de los concejales en 2009

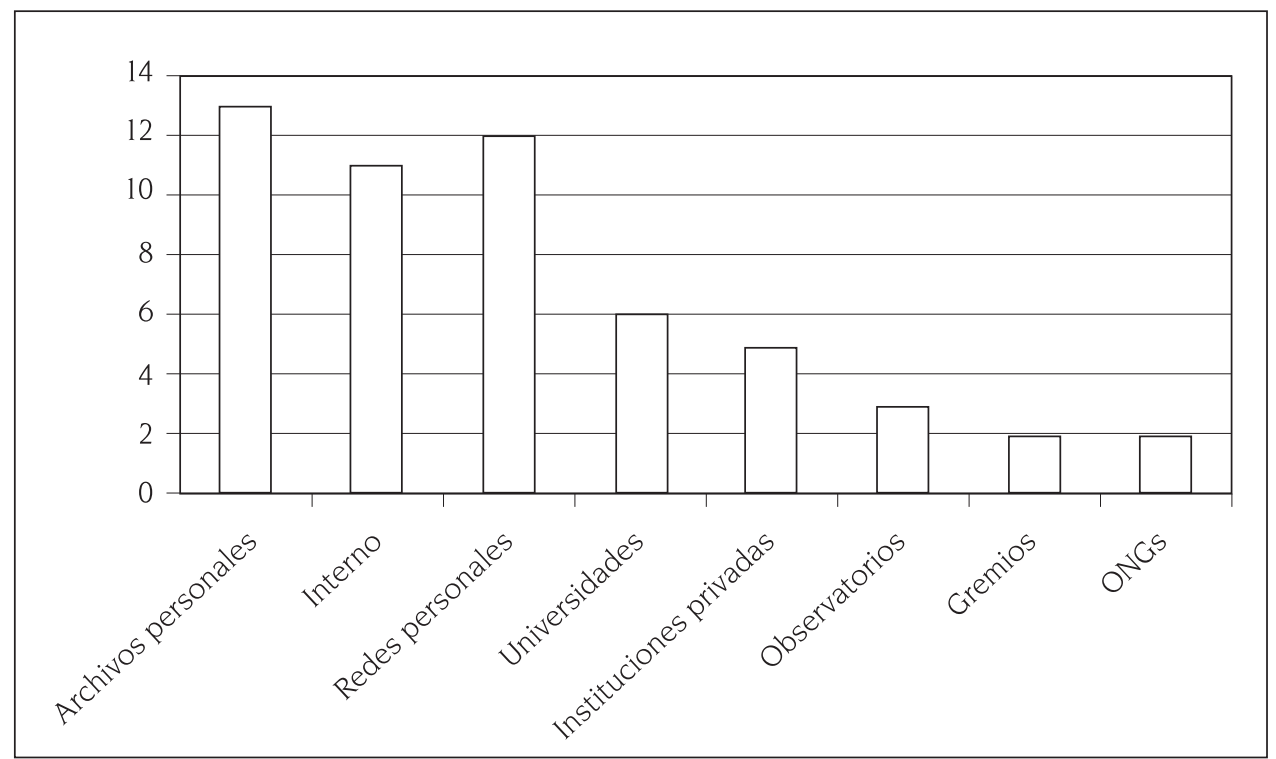

Fuente: elaboración propia

El gráfico anterior muestra con más claridad el diagnóstico que ya ha sido esbozado. Como se ve allí, la información interna del concejal, la de la misma alcaldía, y la de redes individuales tiene más relevancia que la de actores como universidades, ONG, observatorios, y agremiaciones. Esto implica, como ya señalaba Barberena (2010, p. 69) para todos los Concejos del país, que "los debates y propuestas que surgen en el seno de estas corporaciones son muy pobres y se anteponen claramente prioridades particulares a debates sobre el bien general". Lo anterior implica que los secretarios y técnicos de la alcaldía eran capaces de superar los argumentos de los concejales, ya que los primeros cuentan con un gran equipo técnico de apoyo, mientras que los segundos, no. Al indagar por este desbalance técnico, se evidenció que más de la mitad de las unidades de apoyo entrevistadas (54 \%) guardan la información en un archivo único de trabajo, pero que es exclusivo a cada concejal (puede ser visto por su equipo), y el otro porcentaje (46 \%) guardan la información en archivos personales. En ese mismo sentido, al preguntarles a los equipos si estos compartían información sobre las investigaciones, el 40 \% señaló que no lo hacía nunca y el 34 \% que casi nunca. Esto implica que solo un 27 \% de los equipos de los concejales comparte algo de información entre sí, lo que demuestra el mencionado aislamiento. 
Gráfico 2. Periodicidad de intercambio de información entre las unidades de apoyo

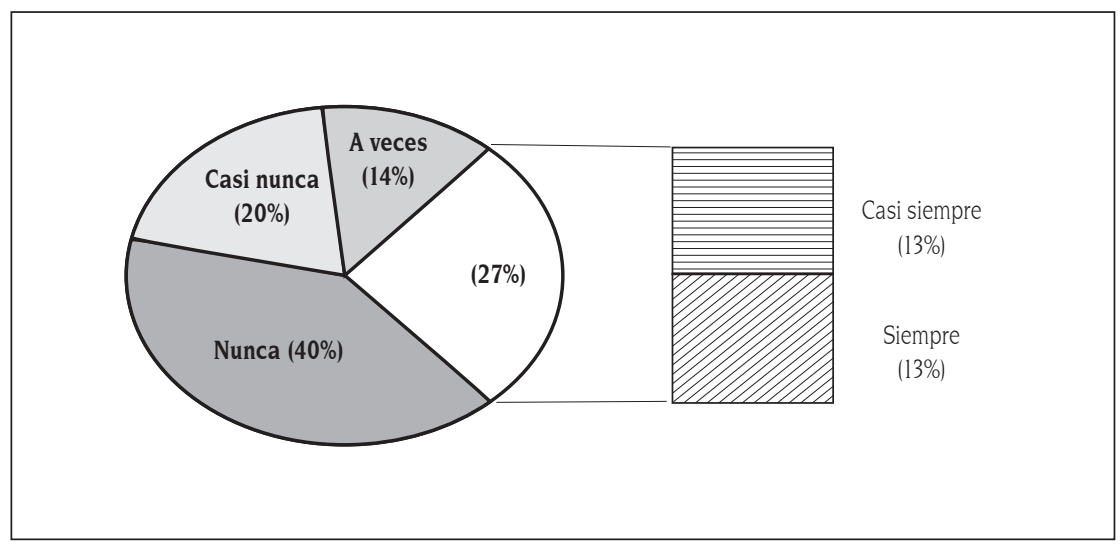

Fuente: elaboración propia

Lo anterior mostraba un escenario en el que el $87 \%$ utiliza como fuentes principales de información datos institucionales brindados por entidades como las secretarías, la Contraloría y la Personería. Todo esto presentaba un escenario bastante lejano de la gobernanza en red de la que se hablaba arriba. La conclusión en torno a un alto nivel del aislamiento y la autarquía en la labor de los concejales muestra que durante la década del 2000 el Concejo limitó la participación ciudadana organizada. En la década del noventa esto se había reflejado en la escasa participación de concejales (y del Concejo) en importantes ejercicios de construcción colectiva de ciudad como el Plan Estratégico de Medellín y el Área Metropolitana 2015 (Alcaldía de Medellín, 1997). Ya en los 2000, al concejo se adaptó a la fuerza a cambios importantes como el Presupuesto Participativo que vino del Acuerdo 043 de 2007, el presupuesto por resultados durante el gobierno 2007-2011, y muchos otros asuntos que minaban su poder de mediación. Sin embargo, el cambio interno como estrategia conjunta de la corporación no se mostró hasta entonces como una apuesta institucional clara. Para concluir, se puede retomar lo que señala Mejía (2009, p. 95-96) después de analizar la agenda de políticas públicas del Concejo entre 1995 y 2006 :

... se suscitan algunos interrogantes, al menos en cuanto a la poca incidencia que, en algunos períodos de sesiones, tuvieron ciertos temas de interés evidente para la ciudad, tal y como lo fueron los asuntos correspondientes a salud y prevención de la enfermedad, empleo y emprendimiento y orden público y seguridad, temas éstos que según las categorías establecidas para el análisis, ocuparon, durante todo el período estudiado, muy poca atención por parte de los cabildantes.

A pesar de lo mostrado, es importante anotar que sí se han dado algunas transformaciones en el Concejo de Medellín, y que estas van creciendo de manera 
¿Un Concejo que se transforma?: el análisis de las relaciones de gobernanza del Concejo de Medellín entre 2008 y 2011

más intensa en los últimos años. Para entender la trayectoria de estos cambios, es necesario regresar al año 2002 cuando el Acuerdo 22 crea al Observatorio de Políticas Públicas del Concejo de Medellín (OPPCM) con el propósito de acompañar al Concejo en el análisis de políticas públicas. Es necesario señalar, según el CIE (2005, p. 2) que este observatorio se crea en 2004 con el propósito de integrar la acción de la sociedad civil al Concejo, de forma que se den las condiciones "para que la sociedad civil también forme parte del diseño, ejecución y evaluación de las políticas públicas locales".

Sin embargo, se apunta en el CIE (2005, p. 2), en estos primeros años la dinámica del OPPCM estuvo atada a realizar análisis muy generales de la administración "en materia de educación, salud, empleo y competitividad" y a realizar compendios de las políticas públicas desarrolladas "por las últimas administraciones, en materia de medio ambiente e infraestructura vial y gobernabilidad". De esta manera, los análisis realmente no lograron impactar la dinámica del Concejo y representaban análisis relativamente infrecuentes que no tenían un impacto sobre el quehacer diario del concejal. Ya para finales de 2006 esta dinámica empezaba a cambiar; en ese año, aun bajo el liderazgo del Centro de Investigaciones Económicas de la Universidad de Antioquia, se organizan nuevas actividades que incluyeron un análisis del tiquete estudiantil como política pública, la realización de un foro sobre el tema en asocio con El Colombiano y la presentación del análisis final al Alcalde de Medellín. Asimismo, se adelantan revisiones de las actas del Concejo y se acompañan diversos eventos. Sin embargo, como se señala en el CIE (2006, p. 1-2) después de un proceso para repensarse, el OPPCM empieza a entender que su trabajo debe darle un mayor protagonismo a transformar la labor de los concejales:

A partir de la discusión se acordó darle prioridad a las actividades que permitieran consolidar el Observatorio con una mayor participación de los concejales, al tiempo que éstos se sintieran servidos por el mismo. De este modo, más que apuntarle a la entrega de un informe final, se acordó profundizar en el proceso de establecer conjuntamente las acciones de acompañamiento al ejercicio de las políticas públicas locales y fue así como se planteó la definición de temas sobre la base de una consulta directa a los concejales y se estableció como meta la elaboración de unos documentos de trabajo y foros de discusión, definiendo como caso piloto el análisis sobre el tiquete estudiantil.

En el año 2008, en la búsqueda de avanzar en esta agenda que no se había movido mucho durante el 2007, el Concejo de Medellín (y su Comisión Primera) deciden operar el OPPCM con el apoyo de la Universidad EAFIT y la Universidad de Medellín. El trabajo partió como se indica en el OPPCM (2008), de un diagnóstico hecho en 2008 por ambas universidades, que señaló que además de aumentar la interacción con los concejales era también importante integrar la voz de los 
observatorios de ciudad al Concejo. Este trabajo inicial identificó que en Medellín existían 20 observatorios de ciudad, y fijó la pauta que era necesario que el Concejo se vinculara con estos.

Ya para el primer semestre de 2009 se inició la visita a todos estos observatorios y la posterior documentación y sistematización de toda esta información. Como resultado de esto el OPPCM desarrolló una herramienta cualitativa llamada Guía del Concejal' (ver gráfico 3), la cual se puede entender como una gran base de datos de temas de ciudad, alimentada por los análisis de más de veintiséis (26) organizaciones que incluyó observatorios, ONG, centros de investigación, y entidades públicas. Esto significó que el Concejo empezara a tener la posibilidad para principios de 2010 de contar con la información producida por más de doscientas (200) personas y casi treinta organizaciones de la ciudad. Además, en 2011 también se vinculó a la iniciativa la Federación Antioqueña de ONG y 120 organizaciones allí federadas, formando así alrededor del Concejo de Medellín y de las universidades, una de las mayores bases de datos de información de ciudad.

Este rumbo continúa durante 2010, período en el que el OPPCM alcanza relaciones con 36 entidades que producen información en la ciudad. Inicia también un diagnóstico de la entidades productoras de información de la ciudad (30 entrevistados) (ver Leyva y Tabares, 2011). Recolecta más de seiscientos documentos y más de 6500 páginas de información de ciudad. Esto implicó que el Concejo empezara a contar con una base de datos de ciudad que reunía información independiente y actualizada. En ese mismo sitio web, sistematiza la información de ejecución presupuestal y de seguimiento al Plan de Desarrollo, de manera tal que los equipos de los concejales y los observatorios de la ciudad puedan efectivamente acceder a una herramienta de seguimiento cuantitativo.

Sin embargo, para mediados de 2010 ya era claro que a pesar de los avances, aún existía una distancia entre lo que permitían realizar las herramientas digitales, y lo que realmente se ha incorporado en el diario quehacer de los equipos de los concejales. Uno de los principales impedimentos para avanzar que se reconocía entonces era la alta rotación de los asistentes de los concejales. De esta manera, según se evidenció en las entrevistas con las funcionarias de la Comisión Primera, se empezó a entender que para ampliar las relaciones de la sociedad con el Concejo, era necesario que la información de la primera se adaptara al ritmo del segundo. Lo anterior, siguiendo al OPPCM (2010) llevó a que se reflexionara en esta comisión a finales de 2010 que la conexión entre el OPPCM y el Concejo era aún muy débil, y la relación estaba muy concentrada en los asistentes. Entonces, el equipo de

Ver en http://www.oppcm-eafit.info/ 
¿Un Concejo que se transforma?: el análisis de las relaciones de gobernanza del Concejo de Medellín entre 2008 y 2011

trabajo llega a la conclusión de que para impactar la dinámicas de participación y gobernanza en red era necesario que la información y la misma visión de los actores sociales estuviera disponible al ritmo que el Concejo la necesitaba.

Gráfico 3. Página Principal de Búsqueda de Información consolidada por el OPPCM

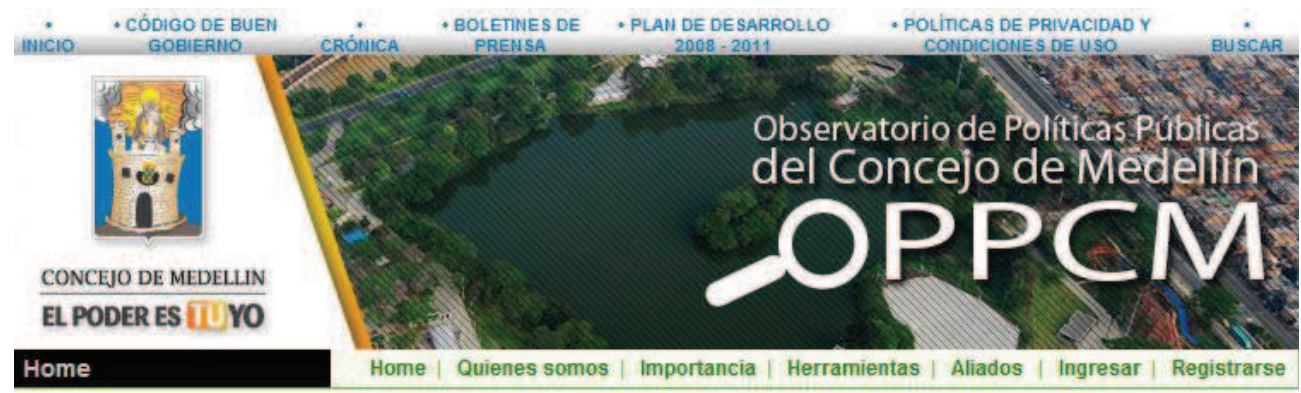

\section{Búsqueda rápida Búsqueda avanzada}

Palabra clave:

Su búsqueda será ejecutada sobre los campos nombre, resumen, descripción y tema, si es un usuario registrado podráacceder a todos los documentos, si es un usuario anónimo su búsqueda se ejecutará solo sobre documentos públicos

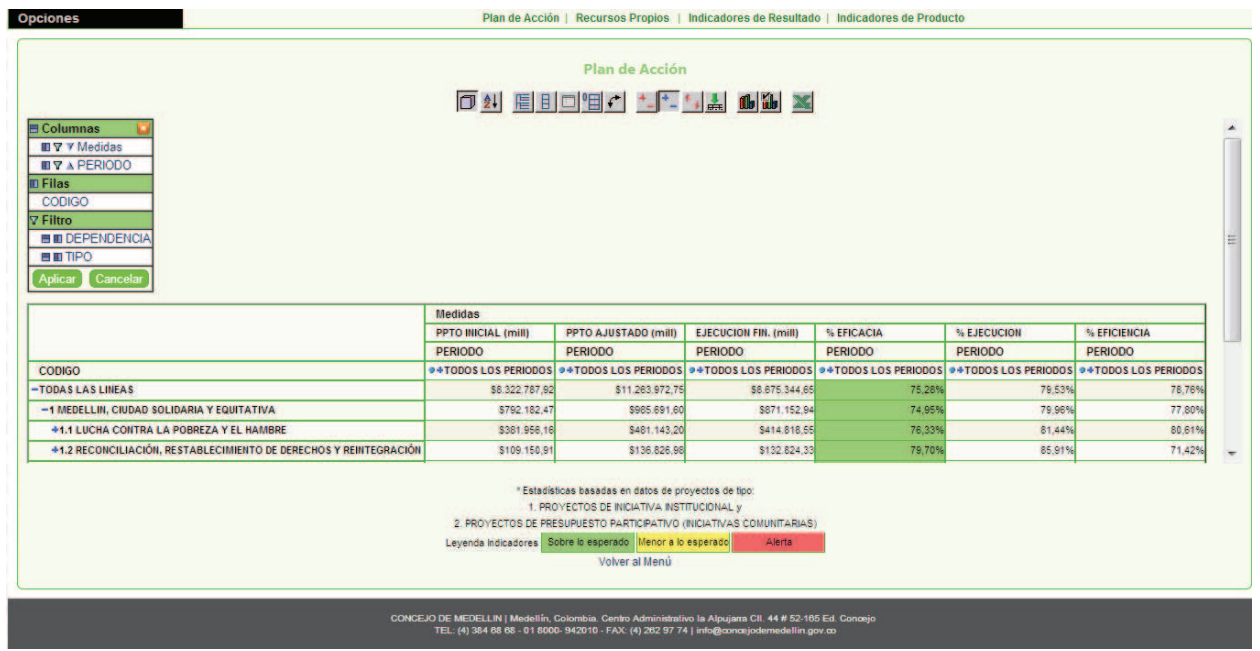

Fuente: tomado de página web OPCCM 
Una corporación como el Concejo de Medellín tiene tres períodos al año en los que se celebran plenarias; en estos períodos cada día se programan temas con algo menos de quince días de antelación. De esta manera, el tiempo que tiene el concejal promedio para preparar un debate — del que no es el ponente principal — no supera las dos semanas de tiempo corrido. Pero, además, cada día hay una o más discusiones sobre temas muy diferentes ${ }^{4}$. Esto implica que para cualquier concejal o su equipo, no hay más que un par de días, quizá horas, para preparar una discusión que puede tener profundas implicaciones para una ciudad como Medellín. Con ello es claro que si no se tiene toda una organización de apoyo a la labor del concejal será muy difícil que su equipo humano pueda responder de forma coherente e incorporar la posición de los múltiples actores urbanos.

Así, en la búsqueda de una respuesta a este reto, el OPPCM empezó a ofrecer información por demanda a los concejales y equipos de apoyo técnico en la segunda mitad de 2010. Esto llevó a que el OPPCM iniciara un acompañamiento continuo a los procesos internos de cada una de las unidades de trabajo de los corporados, con visitas semanales y concertación de temas a investigar, así como con la elaboración de informes detallados que se convierten en el centro de la Plenaria (ver Anexo 2). Esto, se puede suponer, puso al concejo en una situación más ventajosa, pues ya no solo estaba en el papel de escuchar cómo el funcionario de la Alcaldía respondía el cuestionario formulado por el Concejo con quince días de anterioridad, sino que el mismo Concejo podía empezar a presentar su propia posición construida de manera técnica por alguno de los observatorios de la ciudad que trabajan cada tema de forma profunda.

Sin embargo, la frecuencia con que aparece el equipo de trabajo en los debates es esporádica, y los análisis en detalle siguen siendo poco frecuentes. Esto está relacionado con el tamaño del equipo y los recursos disponibles en el OPPCM. En algunos parlamentos en el mundo existe una relación de un miembro de un equipo técnico de apoyo por cada parlamentario; si esto fuera así en el Concejo de Medellín, el OPPCM debería contar con un equipo de, al menos, veinte personas dedicadas a producir información y análisis de la manera como lo hacen organizaciones en el mundo como el Congressional Research Office en EE.UU., la Biblioteca del Congreso en Chile, y la sección de información y documentación del parlamento de Canadá.

En esencia, la evolución descrita muestra cómo el Concejo de Medellín, con apoyo de universidades como la Universidad de Antioquia, la Universidad de Medellín y la Universidad EAFIT, orienta su labor a generar soluciones específicas, oportunas

4 Se pueden presentar en tres días seguidos temas tan disimiles como: la seguridad de la comuna 13 , la situación de los discapacitados, los avances del plan parcial de la Feria de Ganados, y la situación de UNE-telecomunicaciones 
¿Un Concejo que se transforma?: el análisis de las relaciones de gobernanza del Concejo de Medellín entre 2008 y 2011

y técnicas a la labor de control político, con el fin de apoyar a los concejales y equipos técnicos con información cuantitativa y cualitativa básica para el desarrollo de debates. Esto muestra que si bien es un esfuerzo que apenas está en proceso de consolidación, el un camino recorrido en los últimos años, puede servir como experiencia a muchos otros concejos del país.

No obstante, este esfuerzo debe concentrarse, en el futuro, en la necesidad de transferir estas capacidades hacia la estructura organizacional de la corporación (más que en las universidades), de manera que se desarrollen espacios técnicos de análisis, procesamiento y producción de datos económicos y financieros que permitan construir bases de datos y escenarios de gasto independientes a los cálculos de ingresos, gastos, costos e inversión que realiza la Administración municipal. Lo anterior, al comparar estos avances tan importantes del Concejo de Medellín con otros concejos de Colombia, da cuenta del apoyo cada vez más cercano que obtienen los concejales en Medellín.

\section{CONCLUSIONES}

Se puede señalar que el Concejo de Medellín, a pesar de los cambios narrados, ha tenido una estructura de gobernabilidad que responde aún a la lógica de la política más tradicional (con una agenda modernizadora marginal). Es cierto que surgen algunos proyectos modernizadores como la conformación de un Observatorio de Políticas bajo el Acuerdo municipal 22 de 2002; sin embargo, esta misma práctica inicia de forma tímida desde 2003. Este Observatorio representa un paso importante para iniciar la transformación del Concejo, aunque solo de manera tímida, dándole a este una herramienta para superar la uni-direccionalidad en el sentido de la información y le ha dado más independencia al Concejo frente al Ejecutivo. De la misma forma, se ha conectado al Concejo con la sociedad civil organizada, en primera instancia, con los observatorios, y en segunda instancia, con las ONG.

El Concejo de Medellín ha logrado abrir su agenda a la información producida por actores de la sociedad civil, pero no resulta claro que estos realmente logren influir la agenda del Concejo. En este sentido las dinámicas de la corporación aún distan de ser pluralistas, y en algunos casos siguen muy concentradas en la representación de redes políticas tradicionales o de mercado que buscan obtener beneficios a través de la labor de representación.

Se puede concluir que si bien hay avances importantes en la relación de la sociedad civil con el Concejo, estas conexiones son aún incipientes. Se debe recordar que para que exista una verdadera función de meta-gobernanza por parte del Concejo frente a la administración, es necesario que el Concejo se convierta en un articulador 
y facilitador de la participación de la sociedad civil organizada. Como se describe en Berg y Rao (2005, p. 5-6), los concejales podrían jugar un papel clave en asegurar o posibilitar la participación de los líderes no políticos en la toma de decisiones, asegurar la sostenibilidad de las organizaciones de la sociedad civil, y promover la profesionalidad y el diseño institucional de las redes de políticas públicas. Sin embargo, es claro que la confianza, la reciprocidad y la identidad común de las redes de políticas públicas con el Concejo es aún bastante limitada.

Resulta claro por ejemplo que la mayor parte de presupuesto para el apoyo al control político se va para financiar los asistentes individuales de cada concejal. Esto implica que, por un lado, no se logra consolidar un equipo técnico común y, por el otro, que el concejo tiene poco que ofrecer, presupuestalmente hablando, a las organizaciones sociales, observatorios y universidades. Este tipo de esquema deja un gran vacío en términos de recursos para que estos actores realicen estudios y análisis que puedan apoyar la labor de control político del mismo concejo. En este sentido falta ampliar la reflexión y los esfuerzos para conectar al concejo con la sociedad civil organizada; esto parece especialmente importante dado que cada vez se hace más complejo entender la ciudad en términos de su creciente Administración Pública, sus inversiones cada vez más globalizadas y técnicas (por ejemplo EPM), y sus problemáticas sociales cada vez más entrelazadas con fenómenos complejos como las economías criminales y la crisis internacional.

\section{BIBLIOGRAFÍA}

Barberena, Viviana (2010). Las preguntas sin respuestas de la descentralización: la encrucijada y los nuevos caminos, pp. 55-88. En: Fundación Konrad Adenauer Stiftung, Colombia. 25 Años de la Descentralización en Colombia. Fundación Konrad Adenauer Stiftung, Colombia, $180 \mathrm{pp}$.

Berg, Rikke y RAO, Nirmala. (2005). Institutional Reforms in Local Government: A Comparative Framework, pp. 1-14. En: R. Berg y N. Rao. Transforming Local Political Leadership. Basingstoke, Palgrave Macmillan, 224 pp.

Botero, Felipe y Rodríguez, Juan Carlos (2009). Grande no es sinónimo de fuerte. Los partidos y la Reforma Política, pp. 22-49. En Martín Tanaka (editor).La nueva coyuntura crítica en los países andinos. Lima, IEP, IDEA Internacional, 406 pp.

CASTRO, Jaime (2007). ¿Cómo salvar la descentralización?, p. 113-131. En: Darío Restrepo (Editor), Veinte años de la descentralización en Colombia. Bogotá, RINDE, 374 pp.

CIE, Centro de Investigaciones Económicas (2005). Observatorio de Políticas Públicas del Concejo de Medellín. Medellín, CIE-Universidad de Antioquia.

CIE Centro de Investigaciones Económicas (2006). Observatorio de Políticas Públicas de Medellín. Informe final. Medellín, CIE-Universidad de Antioquia. 
¿Un Concejo que se transforma?: el análisis de las relaciones de gobernanza del Concejo de Medellín entre 2008 y 2011

CR-Congreso de la República-(1994). Ley 131. Por la cual se reglamente el voto pragmático y se dictan otras disposiciones. Bogotá, 9 de mayo de 1994, pp. 1-3.

CR- Congreso de la República-(1994). Ley 152. Por el cual se establece la Ley Orgánica del Plan de Desarrollo. Bogotá, Diario Oficial 41.450, 15 de julio de 1994, pp. 28 p.

CR- Congreso de la República-(2003). Acto legislativo 01. Por el cual se adopta una Reforma Política Constitucional y se dictan otras disposiciones. Bogotá, Diario Oficial NN. 45 237, 03 de julio de 1994, 13 pp.

CR-Congreso de la República-(2005). Ley 974. Por la cual se reglamenta la actuación en bancadas de los miembros de las corporaciones públicas y se adecua el Reglamento del Congreso al Régimen de Bancadas. Bogotá, Diario Oficial 45 980, 22 de julio de 2005, 13 pp.

CR-Congreso de la República-(2000). Ley 617. Por la cual se reforma parcialmente la Ley 136 de 1994, el Decreto Extraordinario 1222 de 1986, se adiciona la Ley Orgánica de Presupuesto, el Decreto 1421 de 1993, se dictan otras normas tendientes a fortalecer la descentralización, y se dictan normas para la racionalización del gasto público nacional. Bogotá, 06 de octubre de 2000, $50 \mathrm{pp}$.

CR- Congreso de la República-(1994). Ley 130. Por el cual se dicta el Estatuto Básico de los partidos y movimientos políticos, se dictan normas sobre su financiación y la de las campañas electorales y se dictan otras disposiciones. Bogotá, Diario Oficial N. ${ }^{\circ} 41$ 280, 23 de marzo de 1994, 11 pp.

Dahl, Robert (1961). Who Governs?: Democracy and Power in an American City. Yale University Press, $384 \mathrm{pp}$.

Escobar, Cristina (2002). Clientelismo y ciudadanía: los límites de las reformas democráticas en el departamento de Sucre. En: Análisis Político, N. ${ }^{\circ}$ 47, septiembre a noviembre, pp. 36-54.

Gutiérrez, Francisco (1998). La ciudad Representada: política y conflicto en Bogotá. Bogotá: Tercer Mundo Editores, 246 pp.

Gutiérrez, Francisco (2010). Instituciones y territorio: La descentralización en Colombia, pp. 8-10. En: Fundación Konrad Adenauer Stiftung, Colombia. 25 Años de la Descentralización en Colombia. Fundación Konrad Adenauer Stiftung, Colombia, 180 pp.

González, Esperanza; Velásquez, Fabio (2003). ¿Qué ha pasado con la participación ciudadana en Colombia? Bogotá, Fundación Corona, 455 pp.

Jessop, Bob (2002). The future of the capitalist State. Londres, Polity, 344 pp.

Leal Buitrago, Francisco (1989). El Sistema Político del clientelismo. En Análisis Político, N.o 8, septiembre a diciembre, pp. 8-32

Leyva, Santiago (2010). El proceso de construcción de estatalidad local (1998-2009): ¿La clave para entender el cambio en Medellín?, pp. 271-293. En: Michel Hermelín, Alejandro Echeverri, Jorge Giraldo (Eds). Medellín Medio-Ambiente, Urbanismo, Sociedad. Medellín, Urbam-Universidad EAFIT, 361 pp.

Semestre Económico, volumen 16, №. 33, pp. 181-206 • ISSN 0120-6346, enero-junio de 2013, Medellín, Colombia 
Santiago Leyva Botero • Luis Fernando Agudelo Henao

Leyva, Santiago; Tabares, Juliana (2011). Los observatorios como herramientas de gobierno en las políticas públicas: Descripción de sus orígenes, dinámicas y problemáticas, p 181-207. En: la investigación de las políticas públicas contribuciones desde la academia. Medellín, $\overline{R e}$ Antioqueña de Políticas Públicas, 208 pp.

Martín, Gerard (2012). Medellín tragedia y resurrección: ciudad y Estado. Bogotá: planeta, 350 pp.

Mejía Walker, Carlos (2009). Análisis de la agenda de políticas públicas en el Concejo de Medellín durante el período 1995-2006, Informe Final De Proyectos, pp. 87-98, Segunda Convocatoria Investigación. En Gobierno y Políticas Públicas. Universidad de Antioquia.

Meuleman, Louis (2008). Public management and the metagovernance of hierarchies, networks and markets. Heidelber, Physica-Verlag, 415 pp.

OPPCM (2008). Informe de diagnóstico del OPPCM. Medellín: Universidad EAFIT y Universidad de Medellín.

OPPCM (2010). Acta Universidad EAFIT y Universidad de Medellín. 26 de agosto. Documento Interno.

Parker, Rachel (2007). Networked Governance or Just Networks? Local governance of the knowledge economy in Limerick (Ireland) and Karlskrona (Sweden). En: Journal of Political studies, Vol. 55, pp. 113-132.

Pizarro, Eduardo (2002). La atomización partidista en Colombia: el fenómeno de las microempresas electorales, pp. 357-401. En: Gutiérrez, Francisco (Comp.) Degradación o cambio. Evolución del Sistema Político colombiano. Bogotá, Grupo Editorial Norma, 401 pp.

Pierre, Jon; Peters, B. Guy (2000). Governance, politics and the state. New York Macmillan, 256 pp.

Polsby, Nelson (1960). How to Study Community Power: The Pluralist Alternative. En: Journal of politics, Vol. 22, N. 3 , pp. 474-484.

Sorensen, Eva (2006). Metagovernance the changing role of politicians in processes of democratic governance. En: American review of public administration, Vol. 36, N. ${ }^{\circ} 1$, pp. 98-114. 


\section{ANEXOS}

Anexo A. Unidades de apoyo entrevistadas

\begin{tabular}{|l|l|}
\hline \multicolumn{1}{|c|}{ Nombre del Concejal } & \multicolumn{1}{c|}{ Partido político } \\
\hline Álvaro Múnera Builes & Partido Conservador \\
\hline Aura Marleny Arcila Giraldo & Partido Liberal \\
\hline Bernardo Alejandro Guerra Hoyos & Partido Liberal \\
\hline Carlos Alberto Ballesteros Barón & Polo Democrático \\
\hline Fabio Humberto Rivera Rivera & Partido Liberal \\
\hline Federico Andrés Gutiérrez Zuluaga & Partido social de Unidad Nacional -Partido de la U. \\
\hline Jesús Aníbal Echeverry Jiménez & Partido Colombia Democrática \\
\hline John Jaime Moncada & Movimiento Alas Equipo Colombia \\
\hline José Nicolás Duque Ossa & Partido social de Unidad Nacional -Partido de la U. \\
\hline Juan David Arteaga Flórez & Cambio Radical \\
\hline María Regina Zuluaga Henao & Movimiento Alas Equipo Colombia \\
\hline Nicolás Albeiro Echeverry Alvarán & Partido Conservador \\
\hline Oscar Guillermo Hoyos Giraldo & Movimiento Alas Equipo Colombia \\
\hline Santiago Londoño Uribe & Movimiento Alianza Social Indígena \\
\hline Santiago Martínez Mendoza & Partido Liberal \\
\hline
\end{tabular}

Fuente: elaboración propia 
Santiago Leyva Botero • Luis Fernando Agudelo Henao

\section{Anexo B: Publicaciones del OPPCM}

\section{Boletines completos}

\begin{tabular}{|l|l|c|}
\hline \multicolumn{1}{|c|}{ Fecha } & \multicolumn{1}{|c|}{ Tema } & Nº́ginas \\
\hline Abril 20 de 2010 & Situación de empleo en la ciudad de Medellín & 8 pág. \\
\hline Octubre 6 del 2010 & $\begin{array}{l}\text { Situación de Derechos Humanos en Medellín. Primer } \\
\text { semestre del 2010 }\end{array}$ & 12 pág. \\
\hline Octubre 13 del 2010 & $\begin{array}{l}\text { Encuesta de percepción ciudadana Medellín Cómo } \\
\text { Vamos 2010 }\end{array}$ & 9 pág. \\
\hline Octubre 26 del 2010 & Sistema penal acusatorio & 8 pág. \\
\hline Noviembre 27 del 2010 & $\begin{array}{l}\text { Situación de la calidad del aire en Medellín y el Valle de } \\
\text { Aburrá }\end{array}$ & 9 pág. \\
\hline Febrero 14 del 2011 & $\begin{array}{l}\text { Análisis del Proyecto de Acuerdo 323 del 2011. Metodo- } \\
\text { logía Presupuesto por resultados PPR }\end{array}$ & 9 pág. \\
\hline Marzo 9 del 2011 & Política y Derechos de la mujer & 12 pág. \\
\hline Marzo 16 del 2011 & Plan de Ordenamiento Territorial POT & 9 pág. \\
\hline Marzo 29 del 2011 & Políticas de calidad en la educación en Medellín & 12 pág. \\
\hline
\end{tabular}

Fuente: elaboración propia

\section{Newsletter}

\begin{tabular}{|l|l|c|}
\hline \multicolumn{1}{|c|}{ Fecha } & \multicolumn{1}{|c|}{ Tema } & N páginas \\
\hline Septiembre 28 de 2010 & Informe sobre mercado laboral en Medellín & 2 pág. \\
\hline Noviembre 22 de 2010 & Información sobre desplazamiento forzado en Medellín. & 3 pág. \\
\hline Marzo 22 de 2011 & Información sobre movilidad en Medellín & 2 pág. \\
\hline Agosto 19 de 2011 & Información sobre problemáticas sociales en Medellín & 2 pág. \\
\hline Septiembre 26 de 2011 & Información sobre problemáticas sociales en Medellín & 2 pág. \\
\hline Septiembre 29 de 2011 & Información sobre Derechos Humanos y reconciliación & 2 pág. \\
\hline Octubre 3 de 2011 & Información sobre elecciones y Derechos Humanos & 2 pág. \\
\hline Octubre 10 de 2011 & $\begin{array}{l}\text { Información sobre Consumo en Medellín, Empleo y } \\
\text { Economía. }\end{array}$ & 2 pág. \\
\hline Octubre 24 de 2011 & Información sobre Democracia e Infancia & 2 pág. \\
\hline Octubre 26 de 2011 & Información sobre Prevención del consumo de Drogas & 2 pág. \\
\hline
\end{tabular}

Fuente: elaboración propia 